\title{
ARTIGO
}

DOI: $\underline{\text { https://doi.org/10.22481/praxis.v15i31.4681 }}$

\section{FORMAÇÃO ACADÊMICA E INFLUÊNCIA DOS PROFESSORES NOS PROJETOS PROFISSIONAIS DE UNIVERSITÁRIOS}

\author{
ACADEMIC EDUCATION AND INFLUENCE OF PROFESSORS IN THE \\ PROFESSIONAL PROJECTS OF UNIVERSITY STUDENTS
}

\section{FORMACIÓN ACADÉMICA E INFLUENCIA DE LOS PROFESORES EN LOS PROYECTOS PROFESIONALES DE UNIVERSITARIOS}

\author{
Elzenita Falcão de Abreu \\ Universidade Federal do Vale do São Francisco - Brasil
}

Heloisa Moulin de Alencar

Universidade Federal do Espírito Santo - Brasil

Leandra Lúcia Moraes Couto

Universidade Federal do Espírito Santo - Brasil

\begin{abstract}
Resumo: Buscamos conhecer, sob a perspectiva de estudantes universitários, os pontos positivos e negativos da formação acadêmica e discutir, nas perspectivas da moral e da ética, sobre a influência dos professores nos projetos profissionais dos estudantes. Entrevistamos, utilizando o método clínico de Piaget, 51 universitários da área da saúde da Universidade Federal do Vale do São Francisco (UNIVASF), campus Petrolina. De forma geral, os participantes identificam mais pontos positivos do que pontos negativos na formação acadêmica. Além disso, constatamos que aspectos relacionados aos professores, ao relacionamento entre os alunos, à cultura da universidade, dentre outros, são identificados tanto como ponto positivo como ponto negativo. A maioria dos participantes considera que os professores influenciam seus projetos de vida profissional, e de forma positiva. No entanto, embora em baixa frequência, é importante considerar as respostas dos participantes que afirmam que seus projetos não são influenciados pelos professores e, principalmente, aquela que sinaliza que os professores influenciam de maneira negativa. Esperamos que os dados encontrados em nossa pesquisa instiguem trabalhos de intervenção no contexto universitário, proporcionando reflexões a respeito dos princípios que devem nortear um ensino comprometido com a ética e a transformação social.
\end{abstract}

Palavras-chave: Estudante universitário. Professor. Projeto de vida profissional.

\begin{abstract}
We seek to know, from the perspective of university students, the positive and negative aspects of the academic education and to discuss, in the perspectives of morality and ethics, on the influence of professors in the professional projects of students. We interviewed, using the clinical
\end{abstract}


method of Piaget, 51 university students from the health area of the Federal University of the Vale do São Francisco (UNIVASF), Petrolina campus. Overall, the participants identified more positive than negative aspects in academic education. In addition, we found that aspects related to professors, the relationship between students, the culture of the university, among others, are identified as both positive and negative. Most participants feel that professors influence their professional life projects in a positive way. However, although at a low frequency, it is important to consider the responses of participants who say that their projects are not influenced by the professors, and especially the one which indicates that professors influence in a negative way. We hope that the data found in our research instigate intervention works in the university context, providing reflections on the principles that should guide a teaching practice committed to ethics and social transformation.

Keywords: Professor. Professional life project. University student.

Resumen: Intentamos conocer, bajo la perspectiva de estudiantes universitarios, los puntos positivos y negativos de la formación académica y discutir, desde las perspectivas de la moral y de la ética, sobre la influencia de los profesores en los proyectos profesionales de los estudiantes. Utilizando el método clínico de Piaget, entrevistamos a 51 universitarios del área de la salud de la Universidade Federal do Vale do São Francisco (UNIVASF), campus Petrolina. De manera general, los participantes identifican más puntos positivos que negativos en la formación académica. Además, constatamos que los aspectos relacionados con los profesores, la relación entre los alumnos, la cultura de la universidad, entre otros, son identificados tanto como punto positivo y negativo. La mayoría de los participantes considera que los profesores influyen sus proyectos de vida profesional, y de forma positiva. Sin embargo, aunque en menor escala, es importante considerar las respuestas de los participantes que afirman que los profesores no influyen en sus proyectos y, principalmente, aquella que indica que los profesores los influyen de manera negativa. Esperamos que los datos encontrados en nuestra investigación inciten a realizar trabajos de intervención en el contexto universitario, proporcionando reflexiones sobre los principios que deben guiar una enseñanza comprometida con la ética y la transformación social

Palabras claves: Estudiante universitario. Profesor. Proyecto de vida profesional.

\section{Introdução}

Um conjunto de fatores vem promovendo novas formas de relação entre professores e alunos. Transformações tecnológicas rápidas e profundas, por exemplo, vêm exigindo substanciais modificações na atividade educativa e na prática docente nos seus diferentes contextos de atuação (FERREIRA, 2009). Com relação ao trabalho do professor de educação superior, que é o foco do presente estudo, Maués (2010, p. 142) afirma que ele "vem se modificando à medida que a educação superior está passando por transformações significativas, sobretudo a partir do final dos anos 1990, recebendo nas últimas décadas uma atenção especial, em função do papel que lhe vem sendo atribuído". Tal nível de ensino pode ser considerado como propulsor do crescimento de um país, do seu desenvolvimento social e econômico (MAUÉS, 2010). Nesse sentido, o autor discute que a análise do trabalho docente na educação superior é um desafio, pois as reformas que vêm se processando na referida 
educação alteram os seus objetivos, interferindo nas atividades desenvolvidas pelos professores.

Ainda segundo Maúes (2010), a identidade da universidade foi 'alterada' e ela possui uma 'nova' configuração, caracterizada pela prática de um capitalismo acadêmico e uma concepção mercantilista. Para ele, o trabalho do docente não pode ser analisado de forma separada de tal contexto, pois as atuais formas de financiamento, gestão e avaliação das instituições de ensino superior têm repercutido no trabalho do professor. De acordo com o autor, "a flexibilização, a precarização, a intensificação, o sofrimento, o adoecimento são expressões hoje que permeiam a vida do trabalhador docente" (MAÚES, 2010, p. 152).

Cirino e Goergen (2016) também discutem a respeito do papel da Universidade e do professor de ensino superior. Para os autores, os objetivos educativos da Universidade deveriam estar ligados à melhoria da qualidade moral da humanidade. No entanto, segundo eles, a educação superior se encontra em um profundo desvio moral. Cirino e Goergen argumentam que o modelo de educação contemporâneo parece estar servindo como meio de venda de serviços, muito mais do que buscando a melhoria da humanidade, suprindo necessidades materiais e morais. Dessa maneira, os autores assinalam que a universidade não pode se propor à mera transferência de conhecimento aos indivíduos, e os educadores que nela trabalham devem ter consciência de suas possibilidades e responsabilidades. Dito de outro modo, a educação para a humanidade depende do compromisso das instituições de ensino e de seus professores, que devem visar à formação de cidadãos em perspectiva de humanidade (CIRINO; COERGEN, 2016).

Pelo exposto, é importante definir o conceito de moral adotado no presente trabalho. Nossa definição tem por base as reflexões apresentadas por La Taille (2006, 2010), que assim como outros autores (RICOEUR, 2014; TUGENDHAT, 2012) atribui definições distintas para os conceitos de moral e ética. Segundo o autor, a moral diz respeito aos sistemas de regras e princípios que responde à pergunta 'como devo agir?'. Os deveres que emanam da moral precisam ser considerados dentro de um projeto de 'vida boa', de um projeto de felicidade relacionado ao plano ético, porque é preciso conhecer a perspectiva ética adotada, para poder compreender o processo que os leva a respeitar suas ações morais. Nessa perspectiva, a ética é definida como a "vida boa' com e para outrem em instituições justas" (RICOEUR, 2014, p. 186). A ética é relacionada à reflexão 'que vida eu quero viver?', ou 'que vida vale a pena ser vivida?'.

La Taille $(2006,2010)$ entende que o sujeito moral faz uso da razão para compreender e interpretar as regras, sendo capaz de utilizar critérios para julgar e decidir como agir. Essa 
dimensão intelectual relacionada ao 'fazer moral' o torna livre para estabelecer suas escolhas. O autor também concebe, além da dimensão intelectual, a existência da dimensão afetiva da moral, na qual se encontra envolvido o sentimento que impulsionará o sujeito à ação. Trata-se do 'querer fazer', pois é preciso escolher quais são esses deveres e que essa escolha tenha um sentido existencial para ele, ou seja, que a felicidade individual que ele busca se estenda a todos os seres humanos e tenha, assim, legitimidade social. Dessa maneira, nessa perspectiva, os valores morais são virtudes como a justiça, a generosidade e a honra.

Com base no que foi exposto, destacamos que neste estudo o tema do projeto de vida profissional será relacionado ao que acabamos de discutir sobre moral e ética. De acordo com Neiva-Silva (2003), a literatura científica tem utilizado diferentes termos como: perspectivas, aspirações, expectativas ou projetos de vida, para versar sobre a crença de realizar ou ver algo realizado em seu futuro. Todos apontam para um planejamento ou esperança de concretizar alguma coisa. Na concepção de Ribeiro (2010), a construção de um projeto de vida no trabalho será resultante de jogo de relações entre instituições sociais (como a família e a escola) entre si e na relação com o sujeito. Sobre este assunto, entendemos que há todo um processo de vivência, que pode nos levar a refletir sobre a vida e a ter um projeto futuro, o qual será baseado em nossos princípios e em nossa própria concepção do que seja viver (LA TAILLE, 2006; 2010). Assim sendo, consideramos que ao se desenvolver um plano de vida (INHELDER; PIAGET, 1970/1976), os valores que norteiam as ações do homem colocarão seus ideais em uma escala, sendo uns subordinados a outros de acordo com os interesses e a vontade que se encontram envolvidos no fazer. Ao planejarmos, procuramos visualizar melhor os caminhos que devemos seguir para alcançar nossos objetivos. Para isso, precisamos considerar claramente quais são nossas metas, e devemos saber quais são os nossos valores, pois deles dependem todo e qualquer projeto, bem como a direção que daremos as nossas vidas.

Isto posto, ressaltamos que as teorizações de La Taille sobre a moral e a ética partem de contribuições de importantes autores da área da Psicologia da Moralidade, como Piaget (1932/1994) e Kolhberg (1992). Para estes autores, há um desenvolvimento da moralidade, que para Piaget (1932/1994) é caracterizado por duas tendências: heteronomia e autonomia. $\mathrm{Na}$ heteronomia, as normas morais ainda não são elaboradas pela consciência, ou seja, não são entendidas com base em sua função social. O dever significa obediência a uma lei apresentada e imposta pelos adultos. Já na fase de autonomia moral a criança liberta-se da obediência estrita às regras e passa a julgar a partir de princípios, compreendendo e interpretando as regras. Por sua vez, Kolhberg (1992) descreve três níveis de desenvolvimento moral, pré- 
convencional, convencional e pós-convencional, os quais são divididos em seis estágios. Assim, para os aludidos autores, ninguém nasce sabendo avaliar o que é certo e errado, bem e mal. Tal juízo é fruto de um processo de construção que se realiza durante a socialização dos indivíduos. Além disso, é relevante destacar que o referido desenvolvimento pode acontecer em diversos contextos, ao longo de todo o ciclo vital do sujeito.

Um dos contextos favoráveis à formação moral dos educandos é o contexto escolar. De acordo com Costa (2001), o ambiente escolar é um espaço privilegiado de aprendizagem. O autor destaca o papel do professor nesse contexto, que para ele é mais do que um simples cidadão, é um produtor de cidadania dentro e fora da sala de aula. Do cotidiano das ações docentes, fazem parte os alunos que estabelecem com eles variados tipos de relações promotoras de aprendizagem. Práticas e vivências devem ser oferecidas para facilitar a discussão, a identificação e a incorporação de valores pelos alunos. É preciso buscar nos seus contextos temas que consigam levá-los a evocar os conteúdos de suas vivências para que possam construir a representação de si mesmo e do mundo que vai orientar sua caminhada e guiar suas escolhas (COSTA, 2001). Quando há preocupação com a formação ética, são discutidas as relações com o outro, bem como as responsabilidades de cada um e os princípios e valores que dão sentido à vida.

Ainda com relação ao papel do professor no contexto educacional, Lazzarin, Nakama e Cordoni Junior (2007) concluíram, pelo resultado da pesquisa realizada, que este profissional é considerado responsável não só pela transmissão dos conhecimentos, como também das experiências. Os autores realizaram uma pesquisa que teve como objetivo analisar a percepção de alunos do curso de graduação em Odontologia da Universidade Estadual de Londrina a respeito do papel do professor cirurgião-dentista no processo de ensino-aprendizagem. Tiveram como participantes 10 acadêmicos do quinto ano do curso, de ambos os sexos, com idades entre 22 e 28 anos, e os dados foram obtidos por meio de entrevistas semiestruturadas. Diante dos resultados, é possível perceber que os alunos não admiram seus professores apenas pelo conhecimento da disciplina que ministra, ou que subsidia suas diferentes atividades acadêmicas, outros valores se encontram envolvidos e são transmitidos no processo de ensino-aprendizagem.

Podemos acrescentar a essa discussão os dados encontrados por Cândido, Assis, Ferreira e Souza (2014), ao investigarem as representações sociais do 'bom professor' de 294 alunos de ensino superior dos cursos de uma universidade pública do Rio de Janeiro. De forma geral, identificaram dois conjuntos de características emitidas pelos participantes atribuídas ao 'bom professor': aspectos relacionados diretamente à profissão e ao papel do 
professor sob uma visão técnica e aspectos que se referem mais à pessoa do professor e não à sua atuação prática. Com base nisso, os estudiosos concluem que o papel do professor como o de mero transmissor de conhecimento vem sendo revisto.

Além do papel do professor, é necessário refletir, também, sobre os sentidos e significados das experiências vividas pelos estudantes no contexto da formação universitária. Partimos do princípio de que a formação do aluno é uma construção coletiva sujeita a uma série de influências, sendo o professor o elemento fundamental nesse complexo de relações. No entanto, outros fatores também afetam a vivência dos alunos no contexto universitário. Como apontam Lameu, Salazar e Souza (2016), ao ingressar na universidade, o estudante pode se deparar com mudanças de residência, afastamento da família, pressões e cobranças (pessoais e sociais), que podem se configurar como potencial estressor e prejudicar o desempenho acadêmico e a qualidade de vida do estudante. Partindo de tal análise, os referidos pesquisadores desenvolveram um estudo com 635 alunos, representantes de 37 cursos de graduação da Universidade Federal Rural do Rio de Janeiro, buscando avaliar a prevalência de sintomas de stress entre os alunos e identificar possíveis fatores de risco ao desenvolvimento de sintomas psicopatológicos. A prevalência de stress entre os universitários foi de $50 \%$, sendo que estes se encontravam em diferentes fases de stress (alerta, resistência, quase-exaustão e exaustão). A fase mais frequente foi a de resistência, sendo os seguintes sintomas mais presentes na referida fase: cansaço constante, pensamento constante em um só assunto, sensação de desgaste físico e problemas de memória. Além disso, é importante destacar que, de uma forma geral, 59\% dos participantes relataram já terem sentido necessidade de atendimento psicológico.

Por sua vez, Faria, Gandolfi e Moura (2014) chamam a atenção para a prevalência de comportamentos de risco em adulto jovem e universitário. As autoras realizaram um estudo transversal com 210 adultos jovens e universitários, de uma instituição superior de Brasília. Os comportamentos de risco adotados pelos estudantes foram: consumo de álcool, uso de motocicletas, hábitos alimentares pouco saudáveis, tentativa de suicídio e excesso de peso. As pesquisadoras relatam que o consumo de álcool foi o comportamento de risco mais prevalente na população pesquisada e, com base em outros estudos, discutem as causas que podem estar relacionadas ao consumo de álcool entre os universitários, como a pressão das atividades acadêmicas, o preço acessível da bebida, a necessidade de fazer parte do grupo, entre outras.

Em consonância com a discussão realizada por Faria et al. (2014), Eckschmidt, Andrade e Oliveira (2013) destacam a dimensão do uso de drogas entre universitários, notadamente no que se refere aos jovens entre 18 e 24 anos. Os pesquisadores buscaram comparar o uso de 
drogas entre os universitários e a população em geral brasileira, dentre outros objetivos. Eles utilizaram dados públicos de levantamentos estatísticos brasileiros realizados com universitários e a população em geral, por meio dos quais verificaram que a frequência de uso de drogas pelos estudantes do ensino superior entre 18 e 24 anos no Brasil é maior que a da população em geral dessa mesma faixa etária. Sobre as possíveis influências para tal diferença, os autores apontam aspectos como o contexto ambiental e as características individuais dos estudantes. Assim, vários fatores contribuem para comportamentos ligados ao uso de drogas na referida faixa etária. Portanto, não há uma solução que seja válida para todos (ECKSCHMIDT et al., 2013). Com relação às estratégias de enfrentamento para tal situação, os autores dão destaque para os programas de triagem e intervenção breve, que podem ser largamente aplicados pelas universidades e possuem boa relação custo-benefício.

Diante do exposto, ressaltamos, com Lameu et al. (2014), que para assegurar uma melhor adaptação do aluno à universidade, e contribuir para sua saúde física e psicológica, se deve investir na convivência dos alunos com a família, permitir maior acessibilidade dos alunos a serviços de Psicologia e Psiquiatria, dentre outras ações. Além disso, concordamos com Bardagi e Hutz (2012) quando destacam o papel dos relacionamentos interpessoais vivenciados no contexto universitário e do envolvimento do aluno em atividades acadêmicas para a sua adaptação à universidade e satisfação com o curso superior, dentre outros aspectos. Os autores buscaram compreender, sob a ótica de alunos universitários evadidos, o impacto específico do envolvimento nas atividades acadêmicas e dos relacionamentos interpessoais, com colegas e professores, na decisão da evasão universitária. Os pesquisadores entrevistaram oito estudantes evadidos, com idades entre 20 e 25 anos, de diferentes cursos de universidades públicas e privadas do Rio Grande do Sul. Referente aos relacionamentos, foi averiguado que os participantes destacam aspectos como dificuldades de interação e pouca identificação de valores e interesses com os colegas como critérios importantes de desengajamento e evasão. Por sua vez, as boas relações de grupo auxiliaram alguns participantes a postergar a saída do curso. A esse respeito, concordando com outros autores, Bardagi e Hutz (2012, p. 180) afirmam que "sentir-se parte do ambiente e do novo grupo é fundamental para a consolidação da identidade profissional, uma vez que o aluno tende a fazer uma associação entre o curso, os colegas, a instituição e a profissão em si”. No que se refere ao relacionamento com os professores, a maioria dos participantes relatou decepção com o tipo de vínculo estabelecido com eles, caracterizando-o como distante, formal. Dessa maneira, os estudiosos citados ressaltam que as verbalizações dos participantes sinalizam a relevância do papel do professor universitário para além da transmissão de conhecimentos, pois são modelos profissionais e 
fontes de apoio e aconselhamento. Quanto à rotina universitária, os alunos descreveram um envolvimento precário com o ambiente universitário, pouca participação em atividades acadêmicas extracurriculares (tais como pesquisa, monitoria e estágio), desconhecimento das oportunidades de engajamento em atividades, entre outros aspectos. Sobre tal dado, os autores destacam a importância das atividades extracurriculares para o enriquecimento da identidade profissional. Nesse sentido, indicam que os alunos sejam desde cedo incentivados ao envolvimento nesse tipo de atividade.

Assim, por considerarmos que o papel do professor é importante para a adaptação do aluno no contexto universitário e para a elaboração de seus projetos profissionais, buscamos conhecer, sob a perspectiva de estudantes universitários, os pontos positivos e negativos da formação acadêmica, bem como investigar de que modo os professores influenciam os seus projetos profissionais. A seguir, apresentamos o método utilizado em nossa investigação e os resultados alcançados.

\section{Método}

Local da investigação

O local da investigação foi a Universidade Federal do Vale do São Francisco (UNIVASF), uma Instituição de Ensino Superior vinculada ao Ministério da Educação, com sede na cidade de Petrolina, Estado de Pernambuco. Foi criada e legitimada pela Lei $n^{\circ}$ 10.473 de 27 de junho de 2002, que a conferiu uma natureza fundacional, para atuação na região do semiárido nordestino, uma região que apresenta um forte contraste social, econômico, ambiental e cultural (UNIVASF, 2004). Suas atividades acadêmicas tiveram início no segundo semestre de 2004, com a missão de ministrar ensino superior, desenvolver pesquisas nas diversas áreas do conhecimento e promover a extensão universitária, caracterizando sua inserção regional mediante atuação multicampi (UNIVASF, 2010). Atualmente, está presente nas cidades de Petrolina/PE (Centro/Ciências Agrárias), Juazeiro/BA, Senhor do Bonfim/BA, São Raimundo Nonato/PI e Paulo Afonso/BA, e oferta vinte e quatro cursos de graduação na modalidade presencial e três na modalidade à distância, além de cursos de Extensão e de Pós-Graduação (UNIVASF, s/d).

A UNIVASF teve como proposta atender, principalmente, a expectativa da população em diminuir a saída dos jovens da região do Polo Petrolina/Juazeiro. O Polo Petrolina/Juazeiro está situado no semiárido nordestino, no submédio São Francisco, e é 
formado pelos seguintes municípios: Petrolina, Lagoa Grande, Santa Maria da Boa Vista, Orocó, em Pernambuco; Juazeiro, Sobradinho, Casa Nova e Curaçá, na Bahia. Assim, entre as principais justificativas para sua implantação está a carência de oferta de educação superior na região semiárida nordestina e a histórica concentração do conhecimento no litoral, desconsiderando o interior nordestino (BRASIL, 2003).

Com a implantação da UNIVASF, torna-se atenuada a força exercida pelas Instituições de Ensino Superior (IES) públicas situadas no arco litorâneo do Nordeste, no que tange à população jovem do Polo Petrolina e Juazeiro em busca de uma qualificação profissional de nível superior. Ao mesmo tempo, vê-se, também, atenuada a força da região no tocante à importação de profissionais de outras áreas do país (BRASIL, 2003).

\section{Participantes}

Os dados foram coletados no campus Petrolina, levando-se em consideração a localização dos três cursos da área da saúde escolhidos para esta investigação, que foram: Enfermagem, Medicina e Psicologia. Participaram 51 estudantes, de ambos os sexos, dos três citados cursos, os quais cursavam os primeiros e últimos períodos quando entrevistados. Nesse caso, chegamos à seguinte distribuição: alunos do curso de Enfermagem do $1^{\circ}(n=9)$ e do $8^{\circ}(n=8)$ períodos; de Medicina do $1^{\circ}(n=8)$ e do $11^{\circ}(n=8)$ períodos e de Psicologia do $1^{\circ}(n=9)$ e do $9^{\circ}(n=9)$ períodos.

Instrumento e procedimento

Utilizamos como instrumento a entrevista individual semiestruturada, realizada de acordo com o método clínico proposto por Piaget (1926/2005, 1932/1994). Segundo Delval (2002, p. 70), “a utilização do método clínico baseia-se no pressuposto de que os sujeitos têm uma estrutura de pensamento coerente, constroem representações da realidade à sua volta e revelam isso ao longo da entrevista ou de suas ações". O autor ressalta que, na aplicação do método clínico, o entrevistador tem diante de si uma pessoa única, que tem uma coerência interna, com toda a singularidade e especificidades da condição humana. Dessa forma, utilizando tal método, o pesquisador busca as características gerais das explicações do indivíduo, a maneira como ele resolve os problemas apresentados, como chega às suas explicações, se busca coerência, se percebe as contradições e, também, de forma mais peculiar, o que há de criatividade nas suas respostas.

As questões do instrumento foram: 1. Mencione pontos positivos e negativos da sua 
formação universitária; 2. Quais são os seus projetos profissionais depois de terminar este seu curso de graduação?; 3. Os seus professores vêm exercendo alguma influência nos seu (s) projeto (s) de vida profissional?; 4. (se a resposta $n^{\circ} .3$ for afirmativa) De que maneira os professores vêm exercendo essa (s) influência (s)?

Todos os cuidados éticos foram adotados, de acordo com os padrões da Resolução N ${ }^{\circ}$ 466/2012 (2012) do Conselho Nacional de Saúde (CNS). Após os devidos esclarecimentos sobre a pesquisa, obtivemos a permissão do representante da Reitoria e dos participantes para realização das entrevistas e gravação das mesmas. Respeitamos a vontade dos estudantes de participar ou não da pesquisa e aqueles que aceitaram assinaram um Termo de Consentimento Livre e Esclarecido.

Tratamento dos dados

Os dados foram analisados tendo por base a teoria piagetiana e a sistematização que propõe Delval (2002). A análise foi feita após a transcrição literal das entrevistas. Priorizamos a análise qualitativa e organizamos os dados em categorias, as quais tornaram possíveis as análises que buscamos realizar. Iniciamos com a leitura dos protocolos para a categorização dos dados. No primeiro momento, elaboramos categorias detalhadas para as respostas e justificativas mencionadas. Em seguida, pudemos transformá-las em categorias resumidas para uma análise 'por questão' do instrumento. Ao final, os dados foram contabilizados na forma numérica e em termos percentuais. Utilizamos a seguinte proposição: número de respostas ou justificativas, que formaram cada categoria, dividido pelo total de respostas ou justificativas multiplicado por 100 .

\section{Resultados}

Os participantes foram indagados a respeito dos pontos positivos e negativos da formação acadêmica e da influência dos professores nos seus projetos profissionais (se exercem e de que maneira exercem). Vale destacar que no presente texto apresentamos e discutimos os dados que se mostraram mais relevantes. Com relação aos dados referentes aos cursos e períodos investigados, destacamos que não encontramos diferenças relevantes com relação aos cursos pesquisados. Quanto aos períodos, verificamos apenas uma diferença, que será mencionada em momento oportuno ao longo do texto. 
Primeiramente, as categorias apresentadas foram formadas pelos pontos positivos da formação universitária $(\mathrm{n}=144)$ considerados pelos estudantes, a saber: "professores" $(\mathrm{n}=36$; $25,0 \%)$, "estrutura física da universidade" ( $n=23 ; 16,0 \%)$, "estruturação do curso" ( $n=23$; $16,0 \%)$, "benefício pessoal" $(\mathrm{n}=18 ; 12,5 \%)$, "cultura da universidade" $(\mathrm{n}=14 ; 9,7 \%)$, "relacionamento com colegas ou turma" ( $n=12 ; 8,3 \%)$, "pesquisa e extensão" ( $n=10 ; 6,9 \%)$, "relacionamento com os professores" ( $n=5 ; 3,5 \%)$, e "ensino em geral" $(n=3 ; 2,1 \%)$.

Verificamos que a categoria "professores" contemplou o maior número de respostas. Os participantes consideram os seus professores como 'muito capacitados', 'qualificados', 'têm vontade de ensinar', 'preocupados com o compromisso social e com o cuidado mais humanizado', 'acolhedores' e 'dedicados à turma'. Emanuel ${ }^{1}\left(8^{\circ}\right.$ p. $)$ relata: “É que os professores passam para a gente o cuidado mais humanizado, que temos que ser mais humanos. Ver o paciente como um todo, não por partes". Ainda sobre a referida categoria, destacamos um aspecto que chamou a atenção nos relatos dos participantes do curso de Medicina, que foi a gratidão ou admiração por alguns professores, ressaltada pelos oito discentes entrevistados do $11^{\circ}$ período. Os estudantes justificaram, principalmente, pelo empenho que os professores tiveram para conseguir o internato para os alunos.

Em seguida, a "estrutura física da universidade" foi considerada como ponto positivo pelos participantes, que apontam recursos físicos e materiais que favorecem a formação, tais como: 'as instalações, 'os laboratórios', 'o acervo bibliográfico', 'o espaço físico'. Com o mesmo percentual aparece a "estruturação do curso". Nessa categoria foram agrupadas as respostas que compreendem a forma como o curso foi estruturado, favorecendo a boa formação. Encontramos referências 'ao currículo renovado', 'estágio: quantidade e oferta desde cedo', 'estruturação em módulos', 'disciplinas interessantes', 'ser generalista', entre outras.

Denominamos de "benefício pessoal" a categoria composta pelo conteúdo das respostas que colocam como pontos positivos aspectos que dizem respeito às vantagens pessoais adquiridas durante a formação: 'conhecer muitas pessoas', 'morar com minha família', 'constituição da própria identidade', 'experiência de morar fora de casa', por exemplo: "Experiência de vida por tudo que vi... tudo que aprendi, eu aprendi foi ter mais responsabilidade” (Milton, $11^{\circ} \mathrm{p}$.).

\footnotetext{
${ }^{1}$ Os nomes dos participantes são fictícios e seguiram o seguinte critério de escolha: os participantes do curso de Psicologia terão seus nomes iniciados pela letra "P", os de Enfermagem pela letra "E" e os de Medicina pela letra "M". Quanto aos períodos do curso, correspondem àqueles que os participantes pertenciam, no período da entrevista, e serão indicados pela letra “p”. Ex: Emanuel ( $8^{\circ}$ p.).
} 
Por sua vez, incluímos em "cultura da universidade" as respostas que refletem uma visão ampla da instituição, ou seja, do sistema de ideias, padrões de comportamento e atitudes, crenças e complexo de atividades que a caracterizam, como: "promove o senso crítico do aluno', 'dá oportunidade para você conhecer melhor', 'oferece oportunidades para o aluno buscar fazer coisas', 'a universidade é engajada com os problemas sociais', 'a universidade está preparando pessoas mais dignas, mais humanas', 'professores, coordenação e reitor valorizam muito os valores humanos'. Pedrita $\left(1^{\circ}\right.$ p.) revela essa visão: “Acho que tem um engajamento mais social na Universidade Federal, uma articulação maior dos alunos com problemas sociais, tanto dentro da instituição como fora também”.

Quanto ao "relacionamento com colegas ou turma", foram registradas as respostas que enfatizam o bom relacionamento com os pares como ponto significativo na carreira acadêmica, respostas que valorizam: 'o aumento da rede social', 'o companheirismo dos colegas', 'a convivência boa com a turma', 'a relação entre turmas', 'a interação dos alunos veteranos e os calouros'. Já a categoria "pesquisa e extensão" foi composta pelas afirmativas que destacam a oportunidade oferecida pela universidade para os estudantes realizarem essas atividades, como esclarece Preta $\left(9^{\circ}\right.$ p.): "Gosto da iniciativa de pesquisa e extensão na faculdade, pois assim podemos ter um curso bom, de boa qualidade".

A categoria "relacionamento com os professores" faz referência às respostas que ressaltam a proximidade e a convivência mantida com os professores como algo positivo da formação: 'relação amistosa', 'proximidade com os alunos', 'boa interação com os alunos'. Podemos observar no que foi colocado por Peterson ( $1^{\circ}$ p.): "A maioria é excelente, professores muito interessantes, têm uma convivência com a gente muito bacana, [...] dentro e fora de sala, não é aquela coisa professor versus aluno".

Após a apresentação das categorias estabelecidas pelos pontos positivos $(n=144)$, detalhamos aquelas constituídas pelos pontos negativos da formação universitária $(\mathrm{n}=118)$. São elas: "estrutura física da universidade" (n=38; 32,2\%), "estruturação do curso" (n=26; $22,0 \%)$, “prejuízo pessoal" $(n=17 ; 14,4 \%)$, “professores" $(n=16 ; 13,6 \%)$, “cultura da universidade" ( $\mathrm{n}=11 ; 9,3 \%)$, "desunião entre alunos ou entre cursos" ( $\mathrm{n}=5 ; 4,2 \%)$, "falta de consciência crítica dos alunos" ( $n=3 ; 2,6 \%)$ e "ausência de pontos negativos" $(n=2 ; 1,7 \%)$.

Como podemos observar, algumas categorias receberam a mesma denominação das expostas como pontos positivos. No entanto, agora as respostas descrevem as características negativas de cada uma delas. A "estrutura física da universidade" surge em primeiro lugar, desta vez como um aspecto que dificulta a formação, ou seja, caracterizando a falta ou deficiência de algo, como: 'biblioteca pequena', 'cantina pequena', 'falta do restaurante 
universitário', 'laboratório de informática pequeno', entre outras. O conteúdo da resposta de Maria ( $1^{\circ}$ p.) nos leva a esse entendimento: “O laboratório de informática é muito pequeno, $e$ quando tem uma professora que reserva todos os dias da semana, de manhã e de tarde, você fica uma semana sem usar”. Por sua vez, em "estruturação do curso" os universitários citam a 'desorganização', a 'formação generalista', a 'ausência ou excesso de disciplinas' e a 'carga horária alta'.

A categoria denominada "prejuízo pessoal" diz respeito às respostas que traduzem algumas dificuldades já enfrentadas pelos alunos, ou que vêm enfrentando na trajetória universitária, com conteúdos a exemplo desses: 'problemas de saúde pessoal', 'dificuldades financeiras', 'ficar longe da família', 'falta de tempo para estudar'. Eugênio ( $1^{\circ}$ p.) falou sobre esse tipo de dificuldade: "A parte econômica da minha família de certa forma atrapalha minha formação, porque se eu tivesse condição financeira melhor, teria melhores condições de estudar aqui".

Os "professores", agora, são citados como ponto negativo da formação. Alguns participantes apresentaram os seguintes argumentos: 'estudaram juntos com os alunos', 'falta de didática', 'formação ineficiente', 'falta de compromisso com os alunos', 'menosprezo a outras abordagens', 'falta de interesse em ministrar aula', 'ausência de apresentação das provas dando margem para uma coisa obscura', 'falta de consideração com os alunos'.

A "cultura da universidade", definida anteriormente, também foi criticada pelos acadêmicos nos seguintes pontos: 'falta de assistência estudantil', 'pouca oportunidade de bolsas', 'pouco apoio financeiro para projetos', 'pouco tempo de funcionamento da universidade' e 'funcionário que trabalha só para ganhar dinheiro'.

Alguns conteúdos de respostas tratam da "desunião entre alunos ou entre cursos", como a 'falta de entrosamento entre os campos', 'conflito entre alunos' e 'falta de coletividade entre alunos e entre cursos'. É assim que reconhece Peterson ( $1^{\circ}$ p.): “Falta um pouco do coletivo, da união dos alunos e dos cursos. Vejo um distanciamento grande entre os alunos dos cursos, principalmente, medicina, eles se afastam muito, não sei o porquê". É importante mencionar que as categorias "relacionamento com colegas e/ou turmas" (ponto positivo) contêm respostas de participantes de todos os cursos e períodos investigados. Por outro lado, a "desunião entre alunos ou entre cursos" foi abordada em todos os cursos, mas apenas nos primeiros períodos. Assim, podemos inferir que a desunião, enfatizada pela falta de coletividade, é percebida pelos estudantes ao ingressarem na instituição.

Após a indagação a respeito dos pontos positivos e negativos da formação acadêmica, questionamos sobre os projetos de vida profissional dos estudantes, e as 
respostas fornecidas permitiram estabelecer as seguintes categorias: "pós-graduação" (n=64; 46,7\%), "trabalho em geral" ( $\mathrm{n}=29 ; 21,2 \%)$, "trabalho como professor universitário" (n=16; 11,6\%), "trabalho específico na área" $(n=12 ; 8,8 \%)$, “concurso" $(n=6 ; 4,4 \%)$, "outro curso" $(\mathrm{n}=3 ; 2,2 \%)$ e "outros projetos" $(\mathrm{n}=7 ; 5,1 \%)$. Após a menção dos projetos de vida profissional, perguntamos aos participantes sobre se os seus professores exercem ou não influência nos seus projetos de vida profissional. Conferimos que a maioria ( $n=33 ; 64,7 \%)$ respondeu "sim, de forma positiva"; seguidos daqueles que responderam "não" exercem $(\mathrm{n}=17 ; 33,3 \%)$, e apenas um participante $(\mathrm{n}=1 ; 2,0 \%)$ considera que "sim, de forma negativa". Posteriormente, para aqueles que responderam "sim", questionamos sobre de que maneira seus professores exercem influência nos seus projetos profissionais. Na Tabela 1, encontram-se as categorias que foram construídas com o conteúdo dessas respostas.

Tabela 1: Maneira de influenciar nos projetos de vida profissional: distribuição do número de respostas dos participantes por categoria

\begin{tabular}{lcc}
\hline Categorias/Pelo (a): & $\mathbf{N}^{\mathbf{0}}$. de respostas & Porcentagem/\% \\
\hline Modo como se relacionam com os alunos & 7 & 15,2 \\
Demonstração de conhecimento da área & 7 & 15,2 \\
Transmissão das experiências pessoal e profissional & 6 & 12,9 \\
Discussão e orientação & 4 & 8,7 \\
Entusiasmo no trabalho & 4 & 8,7 \\
Competência demonstrada & 3 & 6,5 \\
Didática utilizada & 3 & 6,5 \\
Postura profissional & 2 & 4,4 \\
Oportunidade que oferece aos alunos & 2 & 4,4 \\
Descompromisso com a profissão & 2 & 4,4 \\
Incentivo aos alunos & 2 & 4,4 \\
Dados perdidos & 4 & 8,7 \\
\hline TOTAL & $\mathbf{4 6}$ & $\mathbf{1 0 0}$ \\
\hline
\end{tabular}

A categoria "modo como se relacionam com os alunos" representa as respostas que colocam a relação satisfatória entre professor-aluno como uma forma de influência nos seus projetos. Os participantes mencionaram os seguintes aspectos: 'boa convivência dentro e fora da sala de aula', 'acolhimento aos alunos', 'apoio que oferecem' e 'confiança'. 'O esclarecimento de Petronila ( $9^{\circ}$ p.) caracteriza o que estamos expondo: "Os professores exercem influência porque são acolhedores, chegam junto... não tem aquela coisa de ser superior. Eu os admiro e aspiro ser igual a eles".

A “demonstração de conhecimento na área" deixa claro que as respostas tratam sobre a influência dos professores pelo conhecimento que transmitem para seus alunos, sendo esse constatado no 'conteúdo das aulas', 'currículo' ou 'domínio da área' de atuação profíssional. 
Os universitários também consideram que são influenciados pelos professores quando estes demonstram ou falam das suas experiências, sejam pessoais ou profissionais, sendo que esse conteúdo resultou na formação da categoria "transmissão das experiências pessoal e profissional".

Algumas respostas $(n=4)$ enfatizam o entusiasmo, a felicidade, o prazer de ensinar manifestado pelos professores na sua prática profissional, daí a categoria "entusiasmo no trabalho". Uma expressão condizente com o exposto é a de Edson ( $8^{\circ}$ p.): "Mostrando para a gente que valeu a pena, que eles estão felizes no que estão exercendo. Isso motiva, principalmente, para uma pessoa que pensa em ser professor".

Verificamos, ainda, referências aos professores que são capazes, seguros no que fazem. Tais respostas foram inseridas na categoria "competência demonstrada". Um desses relatos foi feito por Márcio $\left(11^{\circ} \mathrm{p}\right.$.): "São profissionais que nos deram muita assistência e são conhecidos lá fora como pessoas boas e competentes, profissional e pessoalmente". Da mesma forma, a categoria "didática utilizada" foi constituída pelos conteúdos que fazem referência à arte de ensinar e de fazer aprender, ou seja: à 'maneira do professor ministrar as aulas', 'qualidade dos textos que disponibiliza' e 'dinâmicas que desenvolve em sala de aula'.

$\mathrm{Na}$ categoria "postura profissional" estão as explanações que se referem ao "jeito de trabalhar' docente, como: o posicionamento diante das situações, aparência pessoal e comunicação verbal e não verbal. Por sua vez, em "oportunidade que oferece aos alunos" estão incluídas as respostas que demonstram que os professores oportunizam diferentes tipos de realizações de atividades práticas. Por fim, "incentivo aos alunos", ao conceberem que os professores os levam a procurar curso de especialização, ou a escolherem determinada área.

É importante destacar que o grupo de respostas "descompromisso com a profissão" versa sobre uma influência negativa dos professores nos projetos profissionais dos alunos. Foram citados aspectos como 'desorganização com a disciplina' e 'falta de compromisso com a universidade em geral'.

\section{Discussão}

Ao investigarmos os pontos positivos e negativos da formação acadêmica, constatamos que os universitários emitem mais pontos positivos do que pontos negativos. Além disso, ressaltamos que os participantes divergem na forma de perceber tais aspectos da formação. Os conteúdos de suas respostas propiciaram a formação de categorias semelhantes nos dois aspectos investigados. São elas: "professores", "estrutura física da universidade", 
"estruturação do curso", "cultura da universidade", "relacionamento ou desunião entre alunos e cursos" e "benefício ou prejuízo pessoal".

Com relação aos conteúdos que versam sobre os "professores", encontramos dados semelhantes aos do estudo de Cândido et al. (2014), no que se refere às representações sociais de universitários sobre o "bom professor". Vimos que em nosso estudo foram mencionados aspectos como a qualificação/formação, a didática, a dedicação/compromisso com a turma, entre outros, para embasar o docente como ponto positivo e negativo da formação acadêmica. Na pesquisa de Cândido et al. (2014), a categoria "é didático" foi o grupo de respostas mais mencionado pelos participantes para caracterizar o "bom professor": uma frequência de 244 respostas, o que equivaleu a 38,3\% do total de explanações obtidas. Os autores também verificaram atributos como "possui conhecimento técnico" ( $\mathrm{n}=49 ; 7,7 \%)$, "possui compromisso e profissionalismo" $(\mathrm{n}=17 ; 2,7 \%)$ e "é atualizado" $(\mathrm{n}=10 ; 1,6 \%)$, que se assemelham aos dados encontrados em nosso trabalho.

Já os conteúdos a respeito da "cultura da universidade" apontam para a discussão realizada por Cirino e Goergen (2016) a respeito da finalidade da universidade. Os autores destacam a necessidade de reflexão sobre as formas de atuação da 'universidade contemporânea' e avaliam ser viável o bom uso dos espaços universitários visando ao projeto de uma humanidade melhor do ponto de vista moral.

Por sua vez, temos os conteúdos que tratam do benefício ou do prejuízo pessoal. Esses tipos de respostas chamam a atenção para a saúde física e psicológica dos universitários, uma vez que há estudos que apontam que este público adota comportamentos de risco, como o uso de drogas, tentativa de suicídio e hábitos alimentares pouco saudáveis (FARIA; GANDOLFI; MOURA, 2014; ECKSCHMIDT et al., 2013). Diante de tais dados, é possível questionar se os referidos comportamentos podem estar associados, dentre diversos outros fatores, à alta prevalência de sintomas de stress entre os acadêmicos. O estudo de Lameu et al.(2016) aborda essa problemática. Os estudiosos verificaram uma prevalência de stress de $50 \%$ entre os 635 estudantes universitários investigados. Segundo eles, houve maior ocorrência de stress em estudantes do sexo feminino, bem como em alunos que moram em residências estudantis, públicas ou privadas, e que têm um menor contato com os membros da família.

Sobre os dados acerca do relacionamento ou da desunião com os colegas, o estudo de Bardagi e Hutz (2012) sinaliza a importância dos relacionamentos interpessoais vivenciados no contexto universitário para a adaptação do estudante à universidade e satisfação com o curso superior. Os estudiosos ressaltam que estratégias que promovam maior integração e 
aproximação social no ingresso do aluno na universidade podem contribuir para um melhor aproveitamento da experiência acadêmica.

Verificamos, ainda, conteúdos que tratam da estrutura física da universidade e da estruturação do curso, tanto como ponto positivo quanto como ponto negativo da formação universitária. Além destes, averiguamos respostas sobre a pesquisa e a extensão, apenas como ponto positivo da referida formação. É importante notar que, por meio desses conteúdos, os alunos ressaltam aspectos da universidade que podem, dentre outras coisas, prejudicar a sua participação em atividades extracurriculares, como a falta de estrutura física e o excesso de disciplinas ou carga horária excessiva. Por outro lado, uma boa estrutura, tanto física quanto de estruturação do curso, poderia facilitar a participação dos alunos nas aludidas atividades. Constatamos também, a valorização da pesquisa e da extensão, mostrando que alguns participantes entendem que tais atividades podem favorecer o seu desenvolvimento profissional, a realização de um bom curso. Esses dados vão ao encontro da discussão realizada por Bardagi e Hutz (2012), os quais destacam a necessidade de criação de estratégias para melhorar o envolvimento do aluno com o curso e a instituição. Os autores discutem, ainda, a importância de que o aluno seja incentivado a se envolver em atividades desde o início do curso, para ampliar a sua experiência acadêmica e facilitar a avaliação sobre a pertinência do curso escolhido. Ademais, eles indicam a relevância de se discutir a função formadora das atividades em pauta, uma vez que os alunos podem estar subaproveitando as atividades nas quais estão envolvidos, desconhecendo sua importância para a construção da identidade profissional e dos projetos de carreira.

Quanto à influência dos professores nos projetos profissionais dos alunos, verificamos que a maior parte dos universitários considera que os professores influenciam os seus projetos profissionais de maneira positiva. Porém, devemos considerar também as respostas nas quais os participantes mencionam que os docentes não influenciam os projetos profissionais ou influenciam de maneira negativa. Tais dados sinalizam a necessidade de intervenção com alunos e professores, buscando estabelecer uma relação mais positiva no contexto universitário.

Ao questionarmos a respeito da maneira como os professores influenciam nos projetos profissionais dos alunos, identificamos que as duas primeiras categorias estabelecidas, "modo como se relacionam com os alunos" e "demonstração de conhecimento na área" obtiveram o mesmo percentual de respostas. Entendemos que, ao citarem o relacionamento dos professores com os alunos como forma de influência, e também como ponto positivo da formação acadêmica, os universitários enfatizam aspectos envolvidos nas 
dimensões social e afetiva do professor, reforçando que é tão importante a relação que estabelecem com eles quanto o conhecimento que possuem da área. Isso quer dizer que os estudantes se deixam influenciar pelo professor que vai além da competência cognitiva, preocupando-se em proporcionar e se envolver em relacionamentos afetivos satisfatórios com eles. Assim como em outros estudos (BARDAGI; HUTZ, 2012; CÂNDIDO et al., 2014; CIRINO; GOERGEN, 2016; COSTA, 2001; LAZZARIN et al., 2007), esse dado leva ao reconhecimento do papel do professor universitário para além da transmissão de conhecimentos, bem como aponta para a importância dos relacionamentos vivenciados com os professores no contexto universitário. Nesse sentido, ressaltamos que o relacionamento entre professor e aluno deve se pautar no respeito mútuo, na cooperação e na justiça, possibilitando assim o desenvolvimento da autonomia (PIAGET, 1932/1994). Consideramos que com a vivência de valores morais no contexto universitário, notadamente no que se refere à qualidade dos relacionamentos com as pessoas que os alunos admiram e possuem como modelo, como os professores, tais valores podem vir a integrar uma parte central nas representações de si dos educandos, aumentando a probabilidade de que seus projetos de 'vida boa' sejam guiados por princípios morais (LA TAILLE, 2006, 2010).

Além de aspectos ligados ao relacionamento, os estudantes também têm como influência a "transmissão das experiências pessoal e profissional" do docente, o "entusiasmo no trabalho" e o "incentivo aos alunos". Tais grupos de respostas tratam mais de características pessoais relacionadas ao professor do que sua atuação profissional. Vale ressaltar que o estudo de Cândido et al. (2014) encontrou dados semelhantes aos nossos. Os universitários do referido trabalho consideram que um "bom professor" é aquele que "tem bom relacionamento pessoal com os alunos" ( $\mathrm{n}=99 ; 15,5 \%)$, "se preocupa com o futuro do aluno" (n=89; 14\%) e "possui atributos pessoais positivos" ( $n=66 ; 10,4 \%)$. Por outro lado, assim como na pesquisa de Cândido et al. (2014) sobre as representações sociais de um "bom professor", encontramos também grupos de respostas que versam sobre características mais técnicas do professor, como modo de influência nos projetos profissionais dos universitários. Conteúdos de repostas como "competência demonstrada", "demonstração de conhecimento na área", "didática utilizada" e "postura profissional" somam 32,6\% $(\mathrm{n}=15)$ das respostas obtidas em nosso trabalho.

Pelo exposto, os nossos dados mostram que o professor é reconhecido e influencia os alunos por ser um profissional que tem uma formação específica, técnica, e deve ter competência e transmitir conhecimento aos educandos. No entanto, a presença de conteúdos de respostas relacionados aos aspectos relacionais e pessoais do professor nos levam a 
concordar com Cândido et al. (2014, p. 363) quando afirmam que se "fez sentido em algum momento o papel do professor como o de mero transmissor de conhecimentos, atualmente sua importância é bastante reconhecida, sendo sua atuação diretamente relacionada ao futuro do aluno".

\section{Considerações finais}

Com relação aos dados encontrados, podemos notar que os alunos identificam e valorizam diferentes aspectos que estão envolvidos na prática educativa de seus docentes, como: as condutas profissionais (orientação/incentivo à pesquisa e a continuar os estudos), os componentes cognitivos (competência teórica e didática, conhecimento da disciplina e da área) e afetivos (acolhimento, disponibilidade, paciência, apoio, confiança). Assim, chegamos à consideração de que não é suficiente possuir um bom desempenho didático-pedagógico, embora as estratégias de ensino e a bagagem teórica continuem sendo consideradas importantes. O aluno entende que a convivência aberta, acolhedora e respeitosa com seus professores influencia positivamente nos seus projetos profissionais, com possíveis repercussões na atuação prática.

Além disso, nossos dados chamam a atenção para a qualidade da cultura da universidade, que deve expressar a busca por uma melhor humanidade. Nesse sentido, os relacionamentos vivenciados no referido contex to devem estar pautados no respeito mútuo, na solidariedade, na justiça, entre outros valores. Vale ressaltar que os participantes assinalam a importância do relacionamento não só do aluno com o professor, mas também, com os próprios pares. Assim, percebemos que a qualidade do contexto em pauta depende, também, do bom convívio entre os estudantes. Os professores podem estar atentos a este dado, e tentarem promover a cooperação entre os estudantes. É importante notar que em um ambiente mais acolhedor, respeitoso, os alunos e os professores podem encontrar meios para superar os desafios que o contexto acadêmico impõe tanto para os estudantes quanto para os docentes.

Diante disso, consideramos, por um lado, que o professor precisa estar preparado para enfrentar as diferentes situações que podem surgir na dinâmica do seu trabalho. Por outro lado, avaliamos que a estrutura da universidade precisa ser modificada para favorecer o bom desenvolvimento do processo de ensino-aprendizagem. Nesse sentido, esperamos que os dados encontrados instiguem trabalhos de intervenção no contexto universitário, proporcionando reflexões a respeito dos princípios que devem nortear o contexto em pauta, favorecendo o desenvolvimento da autonomia e a elaboração de projetos de 'vida boa'. 


\section{REFERÊNCIAS}

BARDAGI, Marucia Patta; HUTZ, Claudio Simon. Rotina acadêmica e relação com colegas e professores: impacto na evasão universitária. Psico (PUCRS), Porto Alegre, v. 43, n. 2, p. 174-184, abr./jun. 2012.

BRASIL. O vale de São Francisco e o Pólo Petrolina - Juazeiro: trabalho do grupo para a implantação da UNIVASF, 2003.

BRASIL. Ministério da Saúde. Resolução 466/12, de 12 de dezembro de 2012. Aprova as diretrizes e normas regulamentadoras de pesquisas envolvendo seres humanos. Brasília, 2012. Disponível em: http://conselho.saude.gov.br/resolucoes/2012/Reso466.pdf

CÂNDIDO, Cássia Marques; ASSIS, Monique Ribeiro de; FERREIRA, Nilda Teves; SOUZA, Marcos Aguiar de. A representação social do "bom professor" no ensino superior. Psicologia \& Sociedade, Belo Horizonte, MG, v. 26, n. 2, p. 356-365, maio/ago. 2014.

CIRINO, Benedito Aparecido; GOERGEN, Pedro. Universidade, relação entre educação superior e ética. Série-Estudos, Campo Grande, MS, v. 21, n. 42, p. 93-105, maio/ago. 2016.

COSTA, Antônio Carlos Gomes da. O professor como educador: um resgate urgente e necessário. Salvador: Fundação Luís Eduardo Magalhães, 2001.

DELVAL, Juan. Introdução à prática do método clínico: descobrindo o pensamento das crianças. (F. MURAD, Trad). Porto Alegre: Artmed, 2002.

ECKSCHMIDT, Frederico; ANDRADE, Arthur Guerra; OLIVEIRA, Lúcio Garcia de. Comparação do uso de drogas entre universitários brasileiros, norte-americanos e jovens da população geral brasileira. J. bras. psiquiatr., Rio de Janeiro, v. 62, n. 3, p. 199-207, set. 2013.

FARIA, Yone de Oliveira; GANDOLFI, Lenora; MOURA, Leides Barroso Azevedo. Prevalência de comportamentos de risco em adulto jovem e universitário. Acta paul. enferm., São Paulo, v. 27, n. 6, p. 591-595, dez. 2014.

FERREIRA, Marco Paulo Maia. O professor do ensino superior na era da globalização. Revista Ibero-americana de Educação, n. 50/5, p. 1-10, out. 2009.

INHELDER, Barbel.; PIAGET, Jean. Da lógica da criança à lógica do adolescente: ensaio sobre a construção das estruturas operacionais formais (LEITE, Dante Moreira. Trad.). São Paulo: Livraria Pioneira, 1976. (Trabalho original publicado em 1970).

KOHLBERG, Lawrence. Psicologia del desarrollo moral. Spain: Desclée de Brouwer, 1992.

LAMEU, Joelma do Nascimento; SALAZAR, Thiene Lívio; SOUZA, Wanderson Fernandes de. Prevalência de sintomas de stress entre graduandos de uma universidade pública.

Psicologia da Educação, São Paulo, n. 42, p. 13-22, jun. 2016. 
LA TAILLE, Yves de. Moral e ética: dimensões intelectuais e afetivas. Porto Alegre: Artmed, 2006.

LA TAILLE, Yves de. Moral e ética: uma leitura psicológica. Psicologia: Teoria e Pesquisa (UnB. Impresso), Brasília, v. 26, n. especial, p. 105-114, 2010.

LAZZARIN, Helen Cristina; NAKAMA, Luiza; CORDONI JUNIOR, Luiz. O papel do professor na percepção dos alunos de odontologia. Saúde e Sociedade, São Paulo, v. 16, n. 1, p. 90-101, Abr. 2007.

MAUÉS, Olgaíses. A reconfiguração do trabalho docente na educação superior. Educar em Revista, Curitiba, n. especial 1, p. 141-160, 2010.

NEIVA-SILVA, Lucas. Expectativas futuras de adolescentes em situação de rua: um estudo autofotográfico. 176f. Dissertação (Mestrado em Psicologia), Universidade Federal do Rio Grande do Sul, 2003. Orientadora: Prof ${ }^{a}$. Dr ${ }^{a}$ Sílvia Helena Koller.

PIAGET, Jean. Introdução - Problemas e Métodos. In: PIAGET, Jean. A representação do mundo na criança (A. U. SOBRAL, Trad., pp. 9-31). (2a ed.) Aparecida, SP: Idéias e Letras, 2005. (Trabalho original publicado em 1926).

PIAGET, Jean. O juízo moral na criança. (2a ed.) São Paulo, SP: Summus, 1994. (Trabalho original publicado em 1932).

RIBEIRO, Marcelo Afonso. A influência psicossocial da família e da escola no projeto de vida no trabalho dos jovens. Pesquisas e Práticas Psicossociais, v. 5, n. 1, São João Del-Rei, p. 120-130, jan./jul. 2010.

RICOEUR, Paul. O si-mesmo como outro (I. C. BENEDETTI, Trad.). São Paulo: Martins Fontes, 2014.

TUGENDHAT, Ernest. Lições sobre ética (9a ed., E. STEIN, revisão e organização da Trad.). Petrópolis: Vozes, 2012.

UNIVERSIDADE FEDERAL DO VALE DO SÃO FRANCISCO - UNIVASF. Estatuto da Universidade Federal do Vale do São Francisco, 2004. Disponível em:

http://www.univasf.edu.br/acessoainformacao/arquivos/estatuto_novo.pdf. Acesso em $20 \mathrm{de}$ dezembro de 2016.

UNIVERSIDADE FEDERAL DO VALE DO SÃO FRANCISCO - UNIVASF. Secretaria de Gestão e Orçamento. Relatório de Gestão. Petrolina, 2010.

UNIVERSIDADE FEDERAL DO VALE DO SÃO FRANCISCO - UNIVASF. Manual do estudante. [s.d.]. Disponível em: http://www.manualdoestudante.univasf.edu.br/. Acesso em: 20 de dezembro de 2016. 


\section{$\underline{\text { SOBRE AS AUTORAS }}$}

\section{Elzenita Falcão de Abreu}

Doutora em Psicologia pela Universidade Federal do Espírito Santo (UFES). Docente do Colegiado de Psicologia (CPSI) da Universidade Federal do Vale do São Francisco (UNIVASF). Membro do Laboratório de Psicologia da Moralidade da UFES (LAPSIM/UFES). E-mail: zeyth@bol.com.br

\section{Heloisa Moulin de Alencar}

Pós-Doutora pela University of California, Berkeley. Doutora em Psicologia pela Universidade de São Paulo. Professora Titular do departamento de Psicologia Social e do Desenvolvimento e do Programa de Pós-graduação em Psicologia da Universidade Federal do Espírito Santo (UFES). Coordenadora do Laboratório de Psicologia da Moralidade (LAPSIM) da UFES. Bolsista Pesquisadora Capixaba da Fundação de Amparo à Pesquisa e Inovação do Espírito Santo (FAPES). E-mail: heloisamoulin@ gmail.com

\section{Leandra Lúcia Moraes Couto}

Doutoranda em Psicologia pelo Programa de Pós-Graduação em Psicologia (PPGP) da Universidade Federal do Espírito Santo (UFES). Bolsista de doutorado da FAPES. Membro do Laboratório de Psicologia da Moralidade da UFES (LAPSIM/UFES). E-mail: leandrabj@hotmail.com 